\title{
Development of Hybrid Composite for Automobile Application and its Structural Stability Analysis Using ANSYS
}

\author{
S. Senthil Murugan* \\ Assistant Professor \\ Department of Mechanical Engineering \\ Mepco Schlenk Engineering College \\ Sivakasi, India,
}

\author{
V. Jegan \\ Assistant Professor, \\ Department of Mechanical Engineering, \\ S. Veerasamy Chettiar College of \\ Engineering and Technology, India,
}

\begin{abstract}
Aluminium metal matrix composite is worth for automobile applications on account of their attractive physical and mechanical propertiess and strength to weight ratio consideration. In this study, composites with two different reinforcements $\left(\mathrm{SiC}, \mathrm{Al}_{2} \mathrm{O}_{3}\right)$ were prepared using stir casting setup. The properties of the developed composites were studied and the values were reported. It was noted that reinforcements increased the strength and reduced the weight of the composites. In this work, Fabrication of composite with Al.6061-20\% SiC- 7\% $\mathrm{Al}_{2} \mathrm{O}_{3}$ for IC engine Pushrod and structural analysis were main objectives. ANSYS workbench software package was utilized to study the structural stability of the pushrod.
\end{abstract}

Keywords: AMC, Stir casting, Push rod, Finite Element Analysis (FEA), ANSYS Software

\section{INTRODUCTION}

In Aluminium alloys, aluminium is the predominant metal. The typical alloying elements are copper, magnesium, manganese, silicon and zinc. Aluminium alloys typically have an elastic modulus of about $70 \mathrm{Gpa}$, which is about one-third of the elastic modulus of most kinds of steel and steel alloys. Therefore, for a given load, a component or unit made of an aluminium alloy will experience a greater elastic deformation than a steel part of the identical size and shape. Metal matrix composites (MMCs), like most composite materials, provide significantly enhanced properties over conventional monolithic materials, such as higher strength, stiffness, and weight savings. While continuous fiber reinforcement provides the most effective strength in a given direction; particle reinforced materials are more attractive due to their cost-effectiveness, isotropic properties, and their ability to be processed using similar technology used for monolithic materials. A large amount of work has been conducted in an effort to characterize the mechanical behavior of particle reinforced metal matrix composites. In this study, aluminium matrix composite is developed for pushrod; which is one of the automobile components.

\subsection{Pushrod}

In a Pushrod IC engine (fig.1, 2) like a Single Overhead Cam engine and double overhead cam engine; the valves are located in the head, above the cylinder. The key difference is that the camshaft on a pushrod engine is inside the engine block, rather than in the head. When the cam rotates, the valve lifter pushes the pushrod upwards. The pushrod moves the rocker arm. Since the rocker arm is pivoted at its center, it pushes the valve off its seat against the spring force. Thus, the valve is opened. When the cam is not in action, the valve returns to its seat by the valve spring and spring retainer. When the valve is maintained opening or closing, it allows the air and fuel and the exhaust emissions contents out of the combustion chamber. Pushrod is a column which is having motion throughout its travel. Due to its angularity load it defects towards the bottom of the column. If diameter of push rod increases, it reduces the deflection and permit to get the optimum valve control. The valve train stability is important when we consider the heavy pushrod. Pushrod mass and stiffness are the two main factors of valve train stability analysis. The mass reduction of the pushrod is achieved by reducing the spring force needed to stop its movement. The major merits of pushrod are high torque during initial move, high acceleration, valve timing accuracy and fuel economic. 


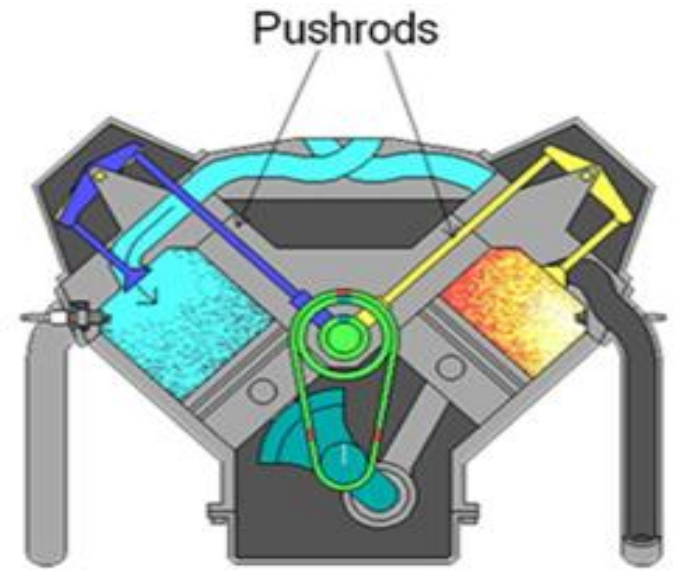

Fig1. IC engine pushrod

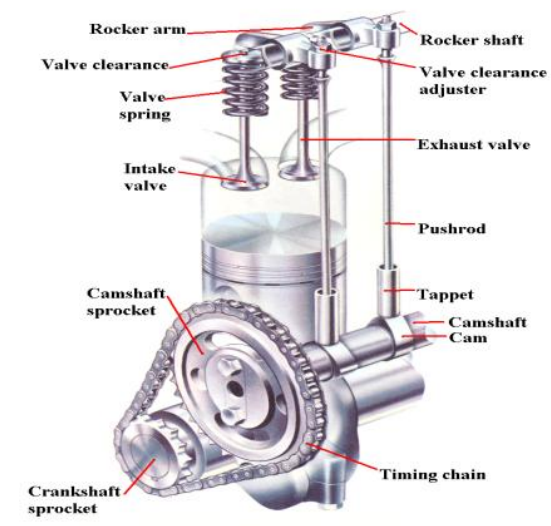

Fig2. IC engine pushrod for V-type

Applications of the pushrod are: pushrod engine is currently used in V-type engine, gasoline engine and radial engine. It is commercially used in NASCAR, NHRA racing car, rear-wheel drive cars and trucks. The pushrod is Commercial Applications in Automobile Industries such as GMC, FORD-Fseries, Chevrolet, Chrysler, Hemi Rolls, and Harly Davidson. Composite materials in IC engine push rod: IC engine pushrod is usually made of steel, Forging, Aluminum Rod, Steel Pipe, and Steel Rod. But in some cases it may be made of polymer matrix composites reinforced with glass fibers. Aluminium matrix composites reinforced with ceramic particles or whiskers have received considerable attention because they can be formed by standard metalworking practices. Properties Required For Push Rod Application: Adequate fatigue strength, higher stiffness, Bending strength, Wear resistance, Reduce vibration, High creep strength, Resistance to corrosion, Resistance to oxidation at the high operating temperatures, Small coefficient of thermal expansion to avoid excessive thermal stress, High thermal conductivity for good heat dissipation.

\subsection{Problem Identification}

Pushrod is being used from the last century. Here, the tapper valve must act under valve-train load at revolution per minute. The fuel entry and the exhaust out are mainly controlled by the actuation of the valves by the pushrod. The mass of the weight and stiffness of the pushrod can affect the engine speed and efficiency. So the design engineer should take care about the new design and in the selection of suitable materials when developing the pushrods. Any type of pushrod failure can affect the engine performance. So it is mandatory to give the due importance to analysis of internal combustion engine valves. Possible modes of pushrod failure are: wear failure, fatigue failure, thermal fatigue, erosion / corrosion, overheating of valves, etc. AMMC is a good choice for the development of pushrod because of its less weight and some significant properties. So the engine makers are mulling to replace the steel made pushrod with the special material having same stiffness and less weight. Aluminium Matrix Composite (AMC) is $40 \%$ lighter than $\mathrm{H}-13$ tool steel. It will have better damping characteristics also. The objectives of the present work are to select base and reinforcement material for pushrod to withstand various loading conditions, and high durability, temperature. To fabricate the $\mathrm{SiC}(20 \%)$ and $\mathrm{Al}_{2} \mathrm{O}_{3}(7 \%)$ reinforced $\mathrm{Al}$. matrix hybrid composite using stir casting techniques. Then the structural stability of hybrid aluminium matrix composite is analysed using ANSYS software. Finally IC engine pushrod is fabricated.

\section{Literature SURVEY}

Kalaiselvan.K et al [1] In this paper, the stir casting technique is the best and widely used for the preparation of metal matrix composites as it is inexpensive. While the rotation of stirrer into the melt, the chemical bonding between the matrix and the reinforcement is better and the achievement of homogeneity is possible. The main parameters which may affect the performance of stir casting process are stirring speed, time, temperature of molten metal and the uniform addition of reinforcement into matrix. Devaraju.A et al. [2] In this paper, Aluminium alloy 6061-T6 is widely utilized in aircraft, defence, automobiles and marine areas due to their good strength, lightweight and better corrosion properties. But, they exhibits inferior tribological properties in extensive usage. In addition, aluminium based composites become brittle by the addition of reinforcements such as $\mathrm{SiC}$ 
and $\mathrm{Al}_{2} \mathrm{O}_{3}$ ceramic particles. Yuhai Dou et al. [3] in this paper, Aluminium Matrix Composites (AMCs) reinforced with ceramic particles have been widely used in the automobile industry, such as pistons and cylinder liners in automotive engines owing to their superior wear resistance. $\mathrm{SiC}$ and $\mathrm{Al}_{2} \mathrm{O}_{3}$ are the most commonly used reinforcements for AMCs due to their high hardness, chemical and thermal stabilities.

Jie Guo et al. [4] in this paper, the dynamic and exciting characteristics of a valve train system are predicted and investigated using a flexible dynamic model. In this model the elastic vibration mechanism of each flexible component is described in a floating reference frame. The mechanical impacts at the valve unseating and seating events are affected by the contact stiffness and damping of contact components. Jie Guo et al.[5]. This paper describe, Component sub models were integrated into the whole valve train model by coupling the corresponding contact and friction forces, and solved simultaneously considering transient effect of lubrication, as well as the torsion and bending vibrations of camshaft. Nagaraj Nayaka et al [6] In this paper, the rate of wear of cam followers in a valve train system is mainly a function of contact stress between the cam and the follower, sliding velocity and hydrodynamic film thickness between the two mating surfaces. The problem of surface fatigue wear becomes severe as the contact between cam and follower exceeds the plasticity limit of material. It finally leads to an increase in valve lash and loss of engine performance. The wear is minimized by reducing the coefficient of friction and by minimizing the compressive stress. Daoud.A et al [7] Studied the frictional behaviour of brake rotor made of aluminum matrix composite (A359 matrix, 20\% Sic reinforcement) utilizing the pin on disc type wear equipment. The wear studies on the commercially used cast iron barke rotor were studied. The results obtained through this investigation showed that the wear rate of the disc made of composite is less than the cast iron during the applied load between 30 to $50 \mathrm{~N}$.

Baradeswaran. A et al [8] this work investigated the influence of graphite on the tribological behaviour of Aluminium $7075 / \mathrm{Al}_{2} \mathrm{O}_{3} / 5 \mathrm{wt}$. \% graphite hybrid composite. The investigation reveals the effectiveness of incorporation of graphite in the composite for gaining wear reduction. Aluminum alloy 7075 reinforced with $\mathrm{Al}_{2} \mathrm{O}_{3}$-graphite were investigated. The composites were fabricated using liquid metallurgy route. Ceramic particles along with solid lubricating materials were incorporated into aluminum alloy matrix to accomplish reduction in both wear resistance and coefficient of friction. Sozhamannan. G.G et al. [9] a literature survey indicates that the major failure mechanism of particle reinforced metal matrix composites such as particle fracture, interfaces decohesion and matrix yielding is mainly dominated by the distribution of particles in the matrix. Hence, analyses were carried out on the microstructure of random and clustered particles to determine its effect on strength and failure mechanisms. The finite element analysis models were generated in ANSYS. The percentage of major failures and stress-strain responses were predicted numerically for each microstructure.

Hayrettin Ahlatci et al. [10], In this paper, Aluminium matrix composites are one of the advanced engineering materials that have been developed for weight critical applications in the aerospace, and more recently in the automotive industries due to their excellent combination of high specific strength and better wear resistance. Bharath.V et al. [11] in this paper, authors confirmed that Metal Matrix Composites (MMCs) are most promising materials in achieving enhanced mechanical properties such as: hardness, Young's modulus, yield strength and ultimate tensile strength due to the presence of micro-sized reinforcement particles into the matrix. Saravanakumar. A et al, [12] authors investigated, MMCs possess combination of metallic properties of matrix alloys with ceramic properties of reinforcements that leads to superior strength and higher service temperature capabilities. Aluminum, magnesium, titanium, and their alloys are commonly used as metallic matrices for the production of MMCs. Habibur Rahman et al, [13] in this paper, AMCs have found wide applications in our daily life. There are some advantages in using particles reinforced AMCs materials than unreinforced materials such as greater strength and high specific modulus, improved stiffness, light weight, low thermal expansion coefficient, high thermal conductivity, tailored electrical properties, increased wear resistance and improved damping capabilities. Reinforcing constituents can be incorporated within the matrix in the form of particles, short fibers, continuous fibers or mono filaments. Now it is used in aerospace, thermal management areas, industrial products, automotive applications such as engine piston, brake disc etc. 


\section{EXPERIMENTAL DETAILS}

\subsection{Fabrication of Composite}

Stir Casting is a liquid state method of composite materials fabrication, in which a dispersed phase (ceramic particles, short fibers) is mixed with a molten matrix metal by means of mechanical stirring as shown in figure 3. Stir Casting is the simplest and the most cost effective method of liquid state fabrication. The liquid composite material is then cast by conventional casting methods and may also be processed by conventional Metal forming technologies.

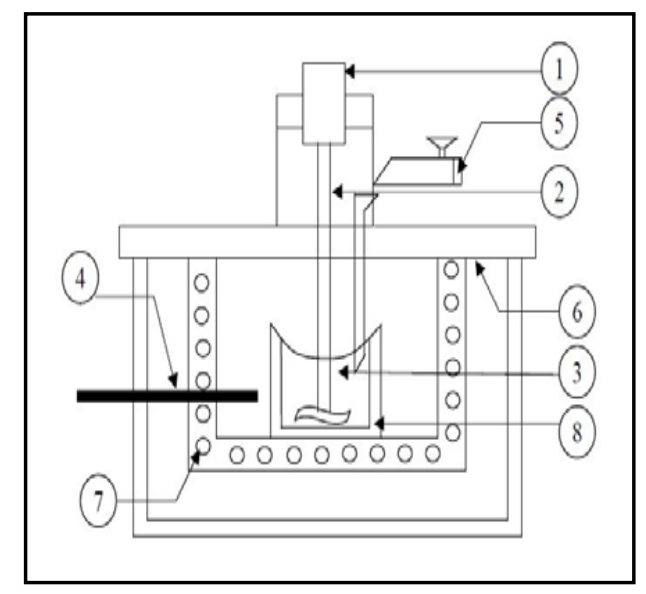

1. Motor

2. Shaft

3. Molten aluminium

4. Thermocouple

5. Particle injection chamber

6. Insulation hard board

7. Furnace

8. Graphite crucible

Fig3. Schematic view of setup for Fabrication of AMC via Stir casting technique

Stir casting setup mainly consist of a furnace and stirring assembly. In general, synthesis of metal matrix composites involves the melt of the selected matrix material followed by the introduction of reinforcement material into the melt, obtaining a suitable dispersion. The next step is the solidification of the melt containing suspended dispersoids under selected conditions to obtain the desired distributions of the dispersed phase in the cast matrix. In preparing the composites through vortex method, the reinforcements are divided into short fibres (whiskers), particulates, long fibres. It is generally mixed along with the base metal to improve their properties and enhance mechanical strength. There are several factors that need considerable attention, including: wet ability between the two main substances, Porosity in the cast metal matrix composites, Chemical reactions between metal and reinforcements, Reinforcement strongly react with base metal solidification of the melt containing suspended dispersoids.

In the present experimental investigation, for pushrod preparation, a new kind of aluminium matrix composite was prepared with aluminium alloy (6061) as matrix and the reinforcements were $\mathrm{SiC}$ (20\%) and $\mathrm{Al}_{2} \mathrm{O}_{3}(7 \%)$. Al6061 is a precipitation hardening aluminium alloy containing Magnesium and Silicon as its major alloying elements. It has good mechanical properties. The melting point of aluminium 6061 is low $\left(660^{\circ} \mathrm{C}\right)$. The role of the reinforcement in a composite material system is fundamentally to increase the mechanical properties of composite. Table 1 shows chemical composition and Table 2 shows properties of Al.6061.

Table1. A6061 alloy composition

\begin{tabular}{|l|l|l|l|l|l|l|l|l|}
\hline Elements & Mg. & Fe. & Si. & Cu. & Mn. & V. & Ti. & Al. \\
\hline Amount (wt. \%) & 1.08 & 0.17 & 0.63 & 0.32 & 0.52 & 0.01 & 0.02 & balance \\
\hline
\end{tabular}

Table2. Properties of aluminium alloy 6061

\begin{tabular}{|l|c|}
\hline \multicolumn{1}{|c|}{ Properties } & Value \\
\hline Density $\left(\mathrm{kg} / \mathrm{m}^{3}\right)$ & 7200 \\
\hline Young's Modulus $(\mathrm{GPa})$ & 80 \\
\hline Thermal conductivity $(\mathrm{W} / \mathrm{mK})$ & 173 \\
\hline Specific Heat $(\mathrm{J} / \mathrm{kg} . \mathrm{K})$ & 896 \\
\hline Poisson Ratio & 0.33 \\
\hline Yield strength $(\mathrm{MPa})$ & 240 \\
\hline Tensile Strength $(\mathrm{MPa})$ & 310 \\
\hline
\end{tabular}


Silicon carbide ( $\mathrm{SiC})$ acts as a good reinforcement with aluminium, titanium etc... it has good tensile strength compared to graphite.

SiC properties are: Low density, High strength, Low thermal expansion, High thermal conductivity, High hardness, high elastic modulus, excellent thermal shock resistance, superior chemical inertness. Table 3 shows chemical composition.

Table3. Silicon Carbide chemical composition

\begin{tabular}{|c|c|c|c|c|c|c|}
\hline Element & $\mathbf{S i C}$ & $\mathbf{S i}$ & $\mathbf{S i O}_{\mathbf{2}}$ & $\mathbf{F e}$ & $\mathbf{A l}$ & $\mathbf{C}$ \\
\hline$\%$ & 98.5 & 0.3 & 0.5 & 0.08 & 0.1 & 0.3 \\
\hline
\end{tabular}

Alumina has high melting temperature around $2000^{\circ} \mathrm{C}$ and excellent properties also. So it is used in many high temperature applications. Table 4 shows Alumina chemical composition.

Table4. Alumina chemical composition

\begin{tabular}{|c|c|c|c|c|c|}
\hline Element & $\mathbf{A l}_{\mathbf{2}} \mathbf{O}_{\mathbf{3}}$ & $\mathbf{T i O}_{\mathbf{2}}$ & $\mathbf{S i O}_{\mathbf{2}}$ & $\mathbf{M g O}$ & $\mathbf{F e}_{\mathbf{2}} \mathbf{O}_{\mathbf{3}}$ \\
\hline$\%$ & 95.69 & 2.66 & 0.83 & 0.29 & 0.28 \\
\hline
\end{tabular}

Aluminum Oxide properties are: Hard, wear-resistant, Excellent dielectric properties from $\mathrm{DC}$ to $\mathrm{GHz}$ frequencies, Resists strong acid and alkali attack at elevated temperatures, Good thermal conductivity, Excellent size and shape capability, High strength and stiffness
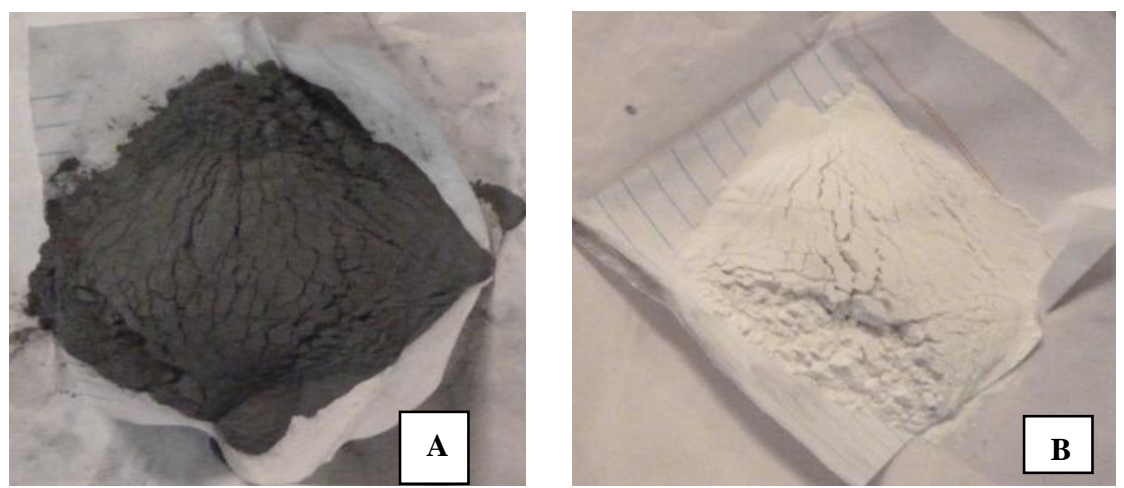

Fig4. Reinforcement powder wt. \% SiC (A) and wt. $\% \mathrm{Al}_{2} \mathrm{O}_{3}(\mathrm{~B})$

Figure $4(\mathrm{~A} \& \mathrm{~B})$ shows the $\mathrm{SiC}$ and $\mathrm{Al}_{2} \mathrm{O}_{3}$ reinforcements respectively. Here two different reinforcement materials will be added into matrix by mixing both. The Aluminium matrix composite consisting of Al.6061, $7 \mathrm{wt} . \% \mathrm{Al}_{2} \mathrm{O}_{3}$ and $20 \mathrm{wt} . \% \mathrm{SiC}$ about an average particulate size of $20 \mu \mathrm{m}$ was prepared by vortex method casting process. $1 \mathrm{~kg}$ of $6061 \mathrm{Al}$ was melted to $780^{\circ} \mathrm{C}$ in a graphite crucible using resistance furnace. The fine vortex was created by the agitation of stirrer into melt.- For removal of dissolved gases from the molten metal, $2 \mathrm{~g}$ of hexachloroethane was added to the molten metal. At the temperature of $800^{\circ} \mathrm{C}$ the preheated $\mathrm{SiC}$ and $\mathrm{Al}_{2} \mathrm{O}_{3}$ particles was added into the vortex with mechanical stirring at $350 \mathrm{rpm}$. Due to the stirring action, the melted aluminum alloy was split into droplets owing to the shear forces brought by the impeller. The stirring is continued to ensure a proper mixing and slurry. The slurry of the composites thus prepared was poured into the preheated steel moulds, which are preheated to $300^{\circ} \mathrm{C}$, at a temperature of $850^{\circ} \mathrm{C}$ and allowed to solidify. Specimens for testing the properties such as hardness, tensile strength, compressive strength, wear test were prepared from these composites. The size of the mould is having diameter of $20 \mathrm{~mm}$ and height $250 \mathrm{~mm} / 110 \mathrm{~mm}$. Figure 5 shows the crucible furnace setup and figures $6 \& 7$ show the cast prepared.
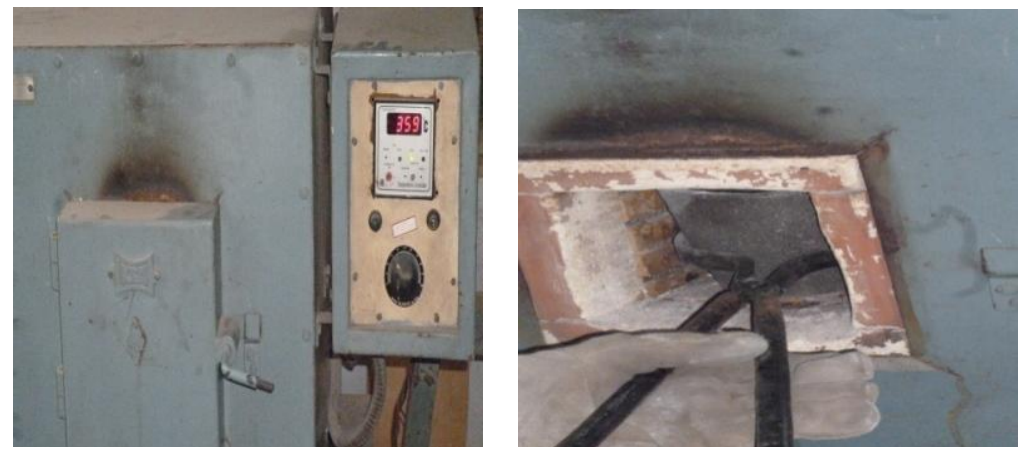

Fig5. Crucible furnace setup 

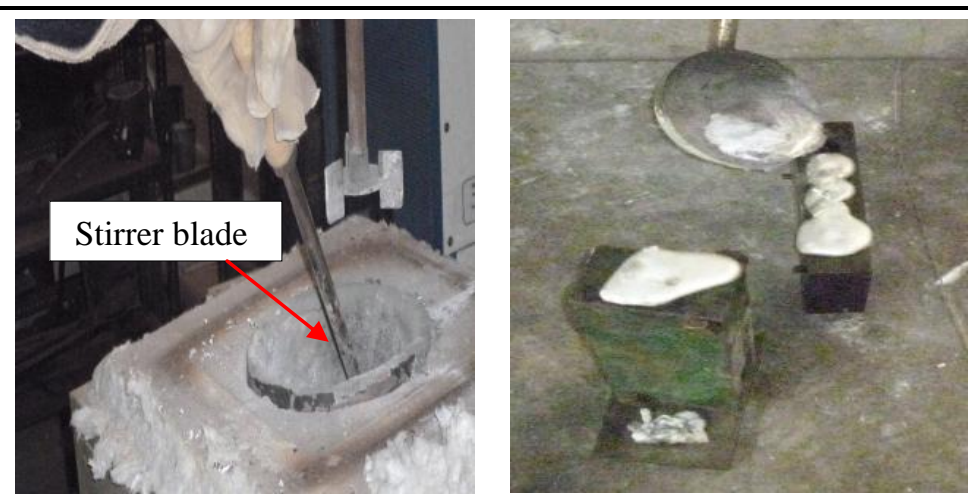

Fig6. Casting of $A M M C$
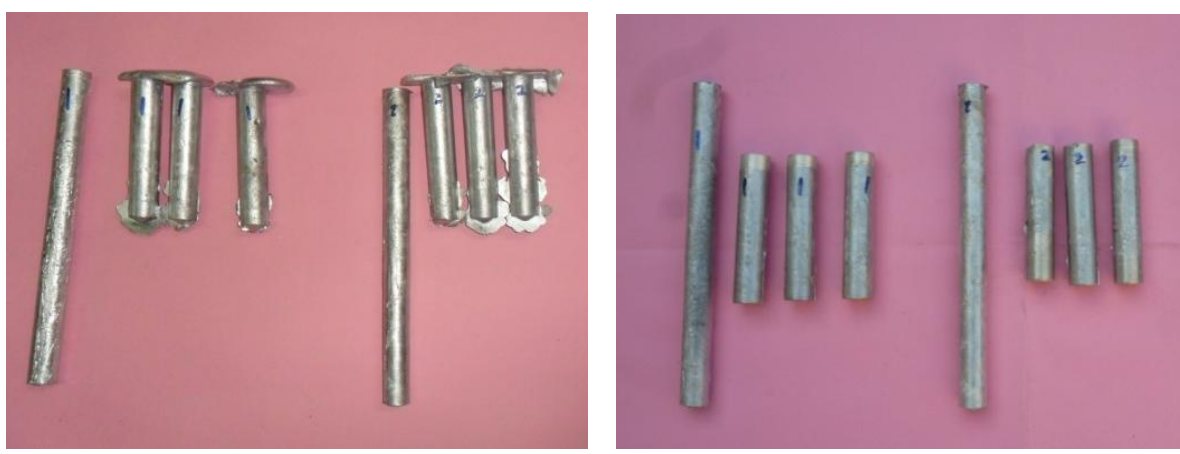

Fig7. Casting of samples and after machined samples

\section{RESUlT AND DisCUSSIONS}

\subsection{Testing}

Testing was done using universal testing machine, Izod impact testing machine and the Rockwell hardness test on the prepared specimen of the composites and the values obtained are given in table 5 .

Table5. Values obtained for prepared AMC

\begin{tabular}{|c|c|c|c|c|c|}
\hline \multicolumn{4}{|c|}{ Average values in N/mm ${ }^{2}$} & \multirow{2}{*}{$\begin{array}{l}\text { Impact strength } \\
(\mathrm{N} / \mathrm{mm})\end{array}$} & \multirow{2}{*}{$\begin{array}{c}\text { Average hardness } \\
\text { (HRB) }\end{array}$} \\
\hline $\begin{array}{l}\text { Tensile } \\
\text { strength }\end{array}$ & $\begin{array}{c}\text { Yield } \\
\text { strength }\end{array}$ & $\begin{array}{c}\text { Fracture } \\
\text { stress }\end{array}$ & $\begin{array}{c}\text { Compressive } \\
\text { strength }\end{array}$ & & \\
\hline 124 & 97 & 110 & 300 & 100 & 52 \\
\hline
\end{tabular}

\subsection{Modelling and Finite Element Analysis (FEA)}

FEA is a numerical and computerized method to predict the force, damping, frequency, vibration analysis, temperature and other effects. FEA analysis, it can be find out the break of material, strength, wear and tear. We can find out require to obtain exact solution to solve exact solution.

In this work, a push rod was fabricated with the developed aluminium matrix composite and with the help of the properties values obtained it was analyzed using Finite element analysis using ANSYS software. Figure 8 shows the proposed pushrod.

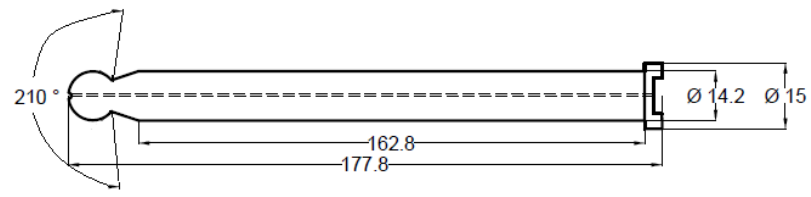

Fig8. Pushrod geometric

IC engine pushrod geometric model was created by using AutoCAD software. Size of Pushrod dimension $=$ pushrod length $177.8 \mathrm{~mm}$ x pushrod diameter $14.2 \mathrm{~mm}$

\section{D Modeling}

The 3D model of pushrod and its assembly were prepared using Pro-E modeling software and are shown in figure $9 \& 10$. The pushrod has a length of $177.8 \mathrm{~mm}$ and a diameter of $14.2 \mathrm{~mm}$. 


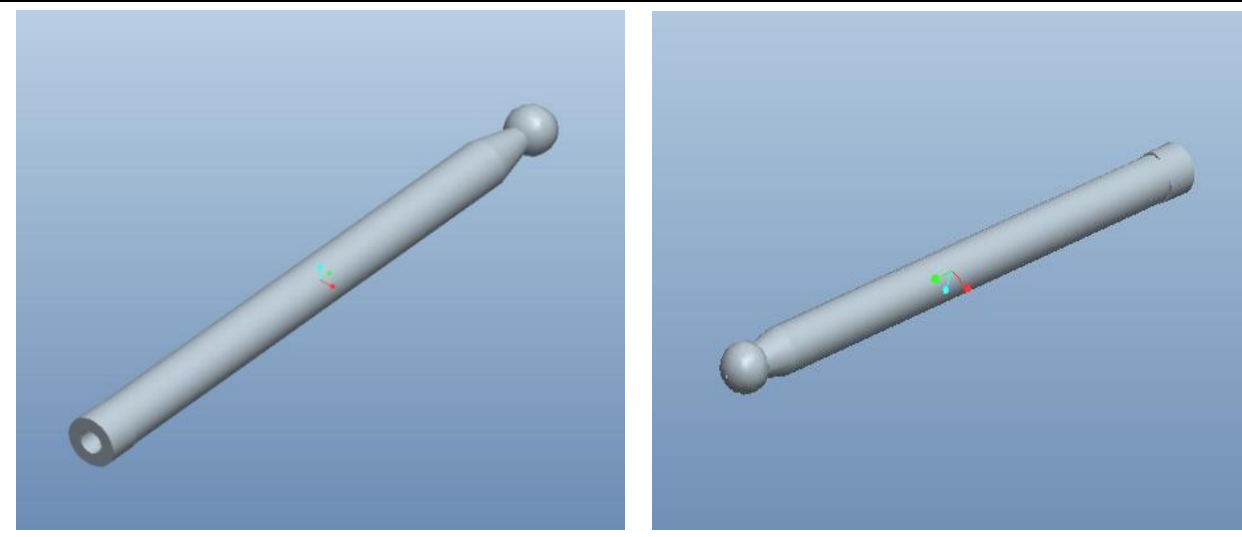

Fig9. Pushrod right side and left side views

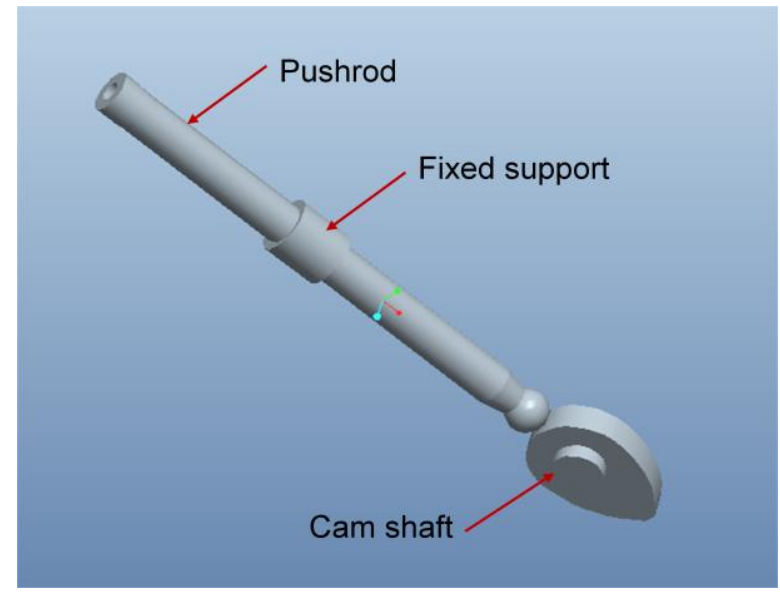

Fig10. Pushrod assembly views

\section{Structural Analysis by ANSYS Workbench Software}

The ANSYS workbench software is suitable to calculate the complex of engineering problem and provide the good design product. FEA is a tool, it can be optimize and generate your simulation and get resolution. This ANSYS workbench software is to easily solve the physical work. The stress distribution of pushrod components was found out. Evaluation of von-mises stresses and displacement plot will help to determine the pushrod performance. The computational steps to be used in the models are described by following figure 11. Figure 12 gives the procedure of FEA (Structural Analysis).

\section{i. Element Type Selection}

- Click Preprocessor > Element type > Add / Edit/ Delete. In the 'Element Types' window, that opens click on Add

- Click on Structural Solid and select 187 elements

\section{ii. Material Properties Selection}

- Click Pre-processor $>$ Material Properties $>$ Material Models. In the window that comes up, select Structural $>$ Linear $>$ Elastic $>$ Isotropic.

- Fill in 1.30e9 for the Young's modulus and 0.3 for minor Poisson's Ratio. Click OK.

The values obtained during testing and calculation for the developed Al6061- 20\% $\mathrm{SiC}$ and $7 \% \mathrm{Al}_{2} \mathrm{O}_{3}$ composite is given in table 6.

Table6. Al6061- 20\% $\mathrm{SiC}$ and $7 \% \mathrm{Al}_{2} \mathrm{O}_{3}$ properties

\begin{tabular}{|c|c|}
\hline Properties & Value \\
\hline Material density $(\rho)-\mathrm{g} / \mathrm{cm}^{3}$ & 2.82 \\
\hline Poisson's ratio & 0.3 \\
\hline Young's Modulus, Gpa & 130 \\
\hline
\end{tabular}




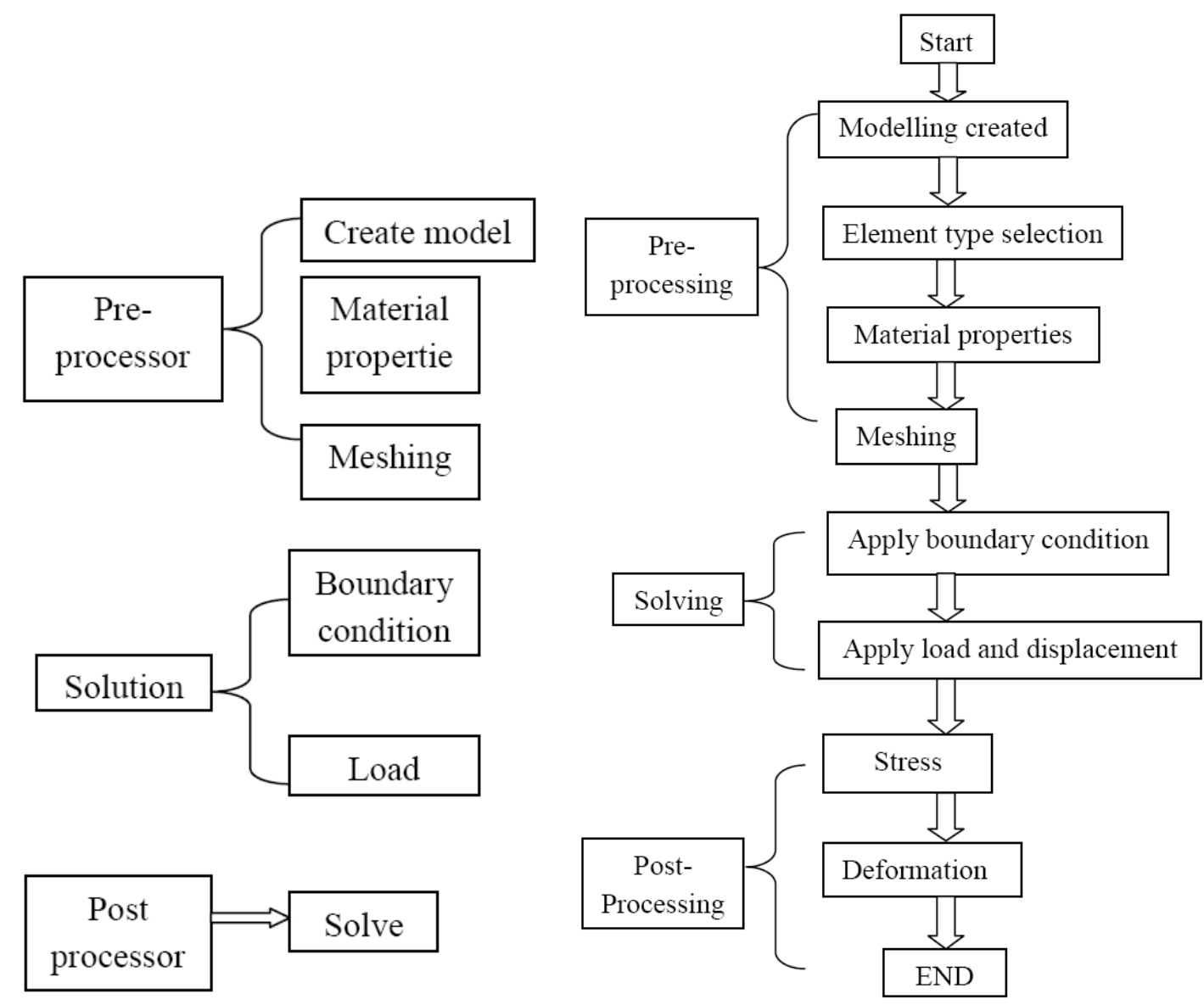

Fig11. Steps in Numerical Analysis

Fig12. FEA flow chart

\section{iii. Meshing}

- Go to Pre-processor $>$ Meshing $>$ Mesh $>$ Volumes $>$ Free.

- Click Pick All in the "Mesh Areas" dialog box. The meshed model looks like this.

Figure 13 shows the pushrod mesh view and figure 14 shows pushrod assembly in meshed view.

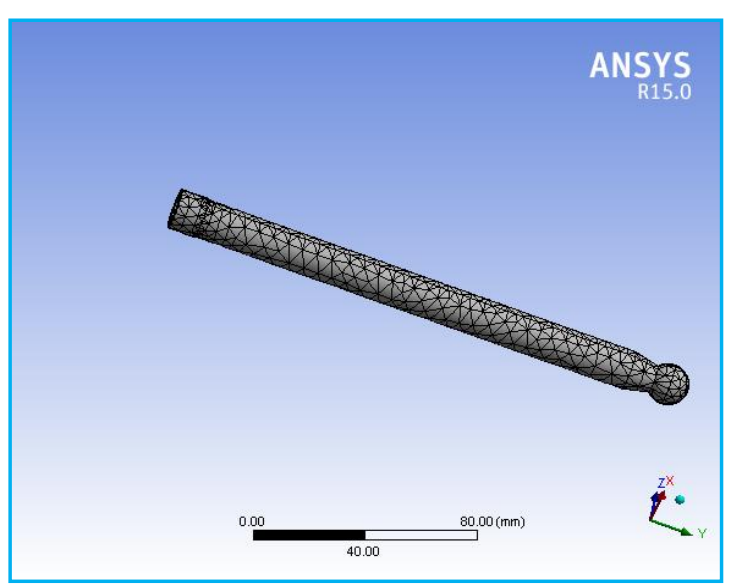

Fig13. Pushrod meshed view

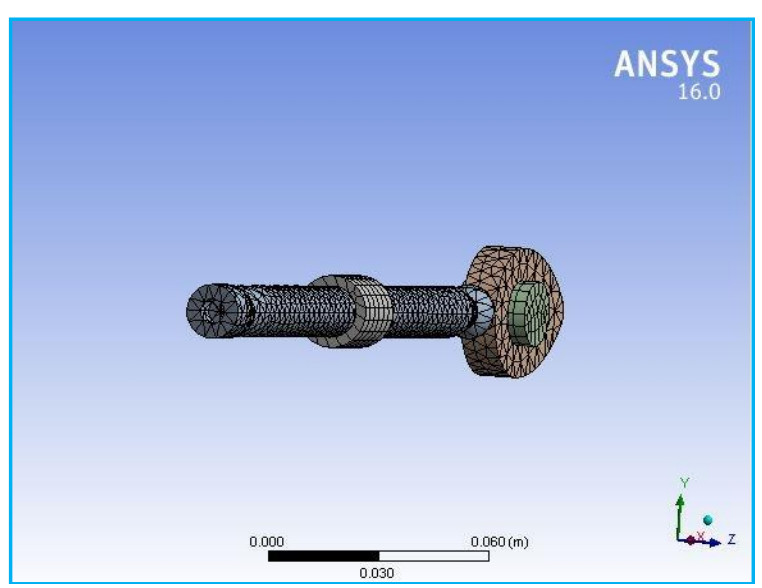

Fig14. Pushrod assembly in Meshed View

\section{iv. Displacement}

- Go to Main Menu Solution $>$ Loads $>$ Define Loads $>$ Apply $>$ Structural $>$ force $>$ On Areas.

- Select All DOF and click OK.

Figure 15 shows the selection of boundary condition on pushrod assembly. 


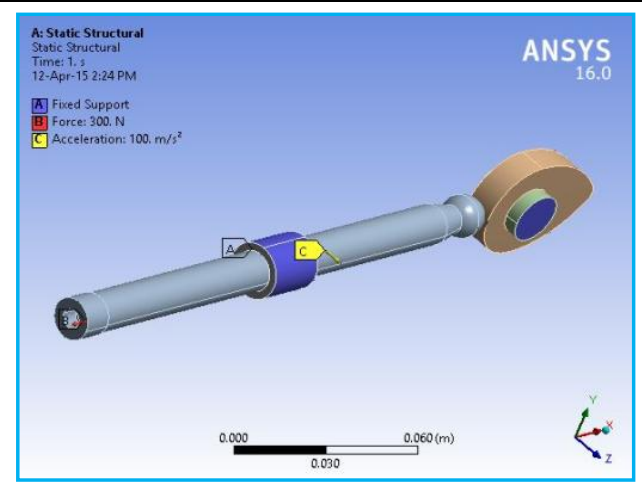

Fig15. Pushrod assembly in Boundary Condition

\section{v. Force/Moment}

- Go to Main Menu Solution > Loads > Define Loads > Apply > Structural > Displacement >on node.

- Select the position of node on pushrod end and click OK. The following window comes up.

\section{vi. Total deformation on pushrod}

- Go to Main Menu Post-Process > Result viewer.

- Select total deformation and Y-component of stress.

Figure 16 (A) \& (B) show the pushrod analysis during CAM dwell (high) and (low) respectively and figure 17 shows the total deformation of pushrod made of the composite.
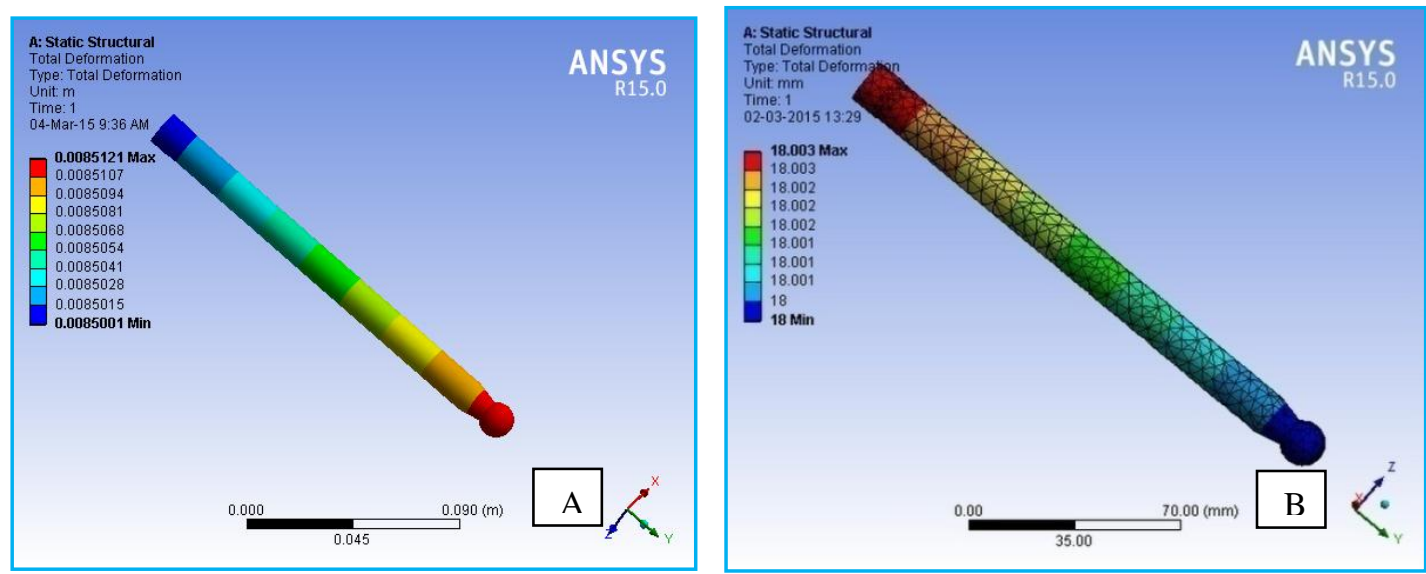

Fig16. Pushrod analysis during CAM dwell-high (A), CAM dwell-low (B)

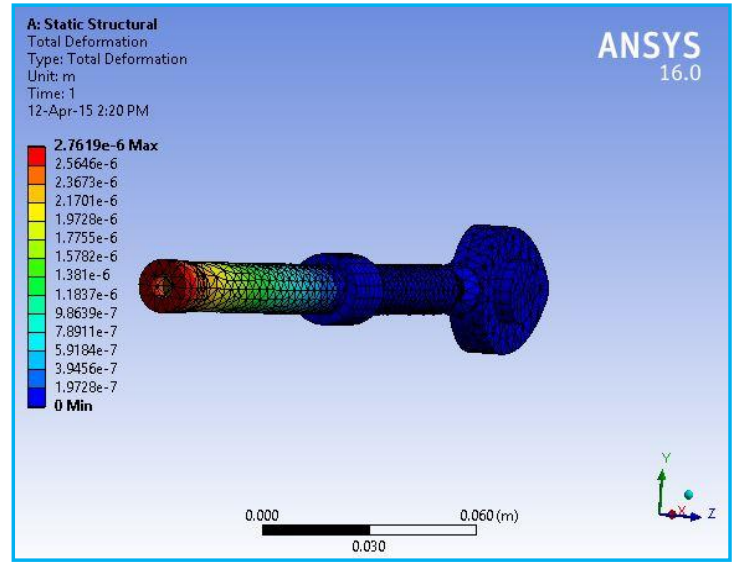

Fig17. Total Deformation analysis on pushrod assembly

From figure 17, figure of deformation analysis we found maximum deformation at pushrod on cap side and found minimum deformation at blue area. The results obtained are given below. 


\section{S. Senthil Murugan \& V. Jegan}

1. Max deformation value is $2.7619 \mathrm{e}-6 \mathrm{~m}$.

2. Min deformation value is $1.9728 \mathrm{e}-7 \mathrm{~m}$.

\section{vii. Stresses on pushrod}

- Go to Main Menu Post-Process > Result viewer.

- Select Stress and Y-component of stress.

Figure 18 is equivalent Von-Mises on pushrod stress analysis and figure 19 shows the Equivalent Von-Mises stress analysis on the entire pushrod assembly.
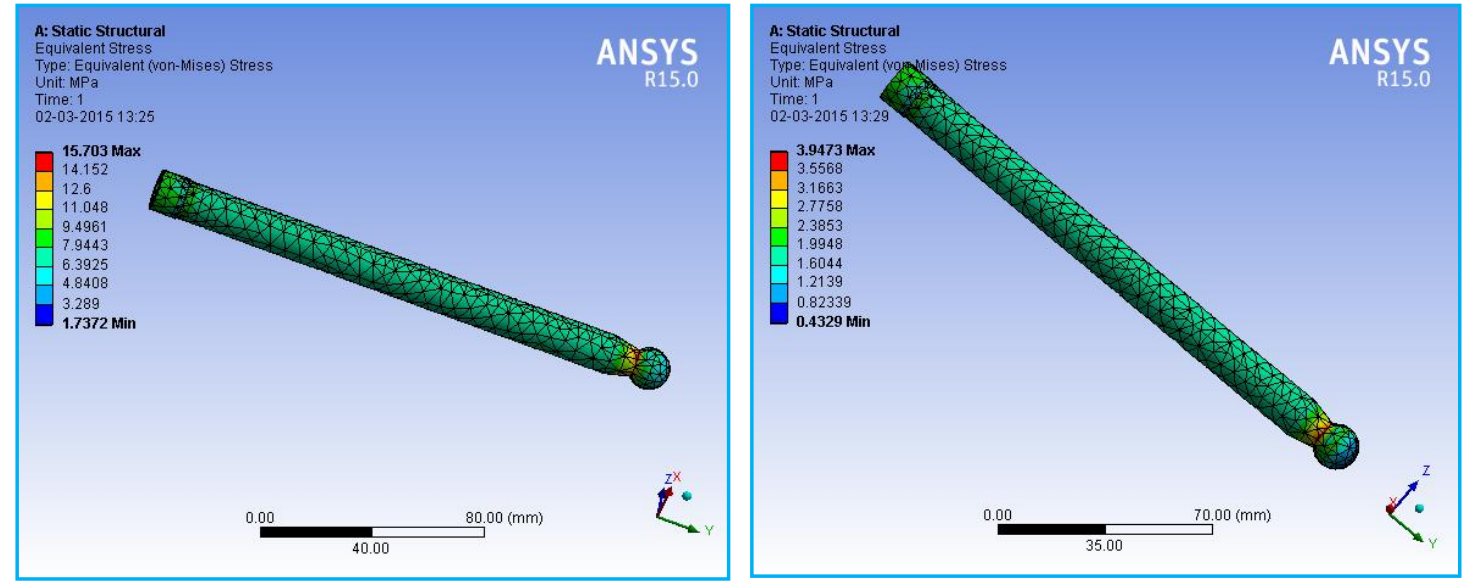

Fig18. Pushrod analysis during CAM dwell (HIGH) \& (LOW)

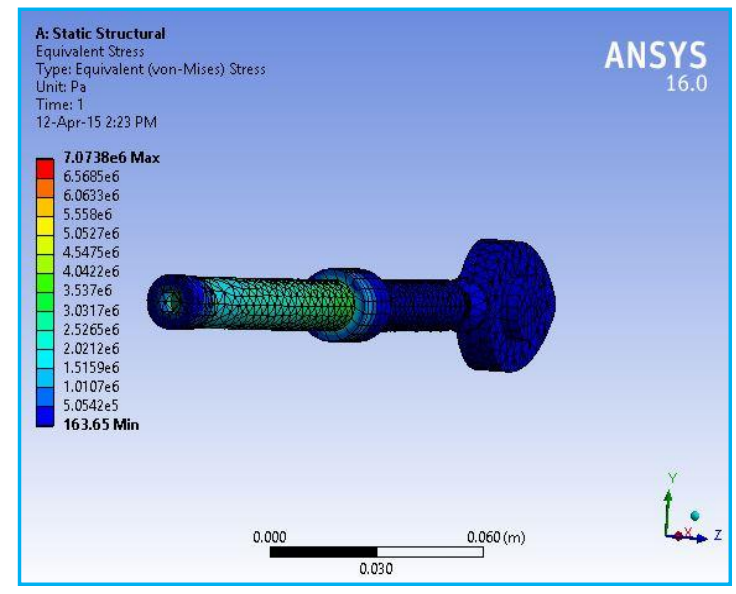

Fig19. Equivalent Von-Mises stress

\section{Stress on pushrod result}

- In this project study about stress on pushrod under condition of static equation.

1. Force along $\mathrm{x}$-axis

2. Fixed of cam shaft and fixed support part.

3. Material properties reference $\mathrm{Al6061}-\mathrm{SiC}$ and $\mathrm{Al}_{2} \mathrm{O}_{3}$.

- From figure of stress analysis we found maximum stress at pushrod inside and found minimum stress at blue area. The results obtained are given below.

1. Max stress value is $7.0738 \mathrm{e} 6 \mathrm{~Pa}$.

2. Min stress value is $163.65 \mathrm{~Pa}$

\subsection{Fabrication of IC Engine Pushrod}

Figure 20 shows the IC engine pushrods which were fabricated from Al6061-20\% SiC and 7\% $\mathrm{Al}_{2} \mathrm{O}_{3}$ hybrid metal matrix composite prepared by stir casting technique. Also the pushrods were machined by using ordinary lathe. 


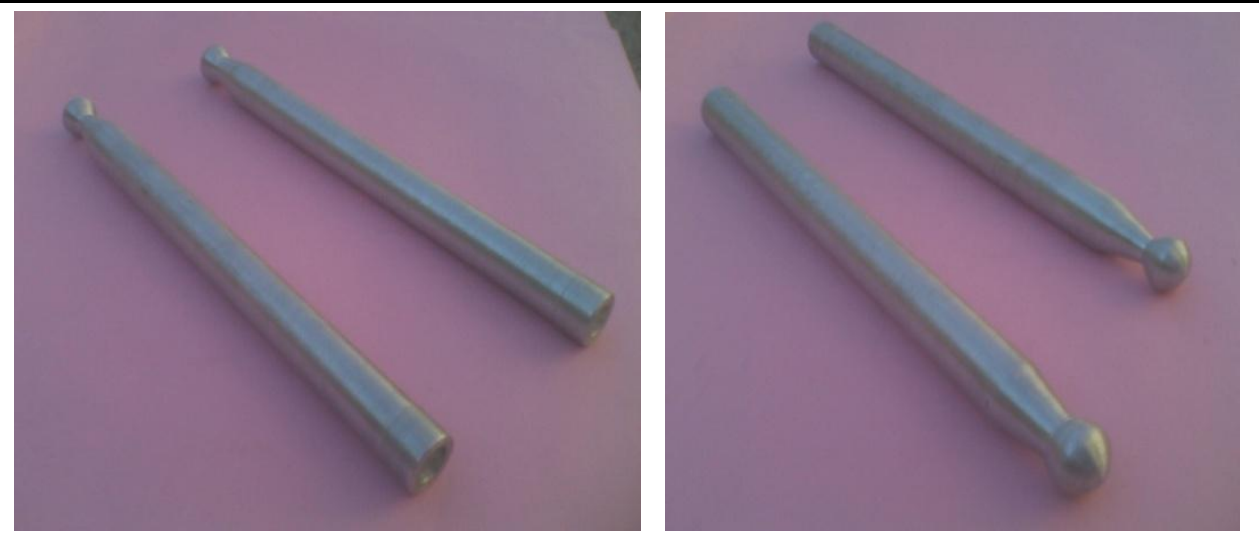

Fig20. IC engine pushrod prepared

\section{Conclusion}

From this study, the following conclusions were drawn.

$>$ The stir casting technique is successfully applied for fabricating Aluminium matrix composite reinforced with $\mathrm{SiC}$ and $\mathrm{Al}_{2} \mathrm{O}_{3}$ for IC engine pushrod application.

$>$ The $\mathrm{SiC}$ and $\mathrm{Al}_{2} \mathrm{O}_{3}$ improves the wear resistance of composites by forming a protective layer between pin \& counter face.

$>$ From this study, the properties for $\mathrm{AA} 6061-7 \%$ of $\mathrm{Al}_{2} \mathrm{O}_{3^{-}} 20$ wt. \% SiC reinforced hybrid particulate Aluminium composites are: the tensile strength is $124 \mathrm{~N} / \mathrm{mm}^{2}$, maximum yield strength is $97 \mathrm{~N} / \mathrm{mm}^{2}$ and maximum fracture stress value observed is $110.2 \mathrm{~N} / \mathrm{mm}^{2}$, compressive strength was noted as $300 \mathrm{~N} / \mathrm{mm}^{2}$, impact strength is $100 \mathrm{~N} / \mathrm{mm}$.

$>$ The present study investigated the static structural analysis of the IC Engine pushrods and its assembly of composition of AA $6061-20 \%$ of SiC-7 \% of $\mathrm{Al}_{2} \mathrm{O}_{3}$ hybrid composite. ANSYS workbench software package was utilized to predict the stress and deformation distribution on the pushrod and the values were noted.

$>$ IC engine pushrods were successfully fabricated for the composition of Al6061-20\% SiC and $7 \% \mathrm{Al}_{2} \mathrm{O}_{3}$ hybrid metal matrix composite.

\section{REFERENCES}

[1] Kalaiselvan.K et al, (2011) "Production and characterization of AA6061-B4C stir cast composite", Materials and Design, vol. 32, pp 4004-4009.

[2] Devaraju.A et al, (2013) "Influence of reinforcements ( $\mathrm{SiC}$ and $\mathrm{Al}_{2} \mathrm{O}_{3}$ ) and rotational speed on wear and mechanical properties of aluminium alloy 6061-T6 based surface hybrid composites produced via friction stir processing", Materials and Design, vol.51, pp 331-341.

[3] Yuhai Dou et al, (2014) "Friction and wear behaviours of B4C/6061Al composite" Materials and Design, vol. 60, pp. 669-677.

[4] Jie Guo et al, (2011) "Investigation of dynamic characteristics of a valve train system", Mechanism and Machine Theory, vol.46, issue 12, pp 1950-1969.

[5] Jie Guo et al, (2014) "Dynamic and exciting analysis with modal characteristics for valve train using a flexible model", Mechanism and Machine Theory 78, 158-176.

[6] Nagaraj Nayaka et al, (2006) "Predictions of cam follower wear in diesel engines". Wear.vol. 260, pp. 181-192.

[7] Daoud.A et al, (2010) "Wear and friction behaviour of sand cast brake rotor made of A359-20 vol\% SiC particle composites sliding against automobile friction material". Tribology International vol. 43, pp. 544-553.

[8] Baradeswaran.A et al, (2014) "Study on mechanical and wear properties of Al $7075 / \mathrm{Al}_{2} \mathrm{O}_{3} /$ graphite hybrid composites" Composites. Part B vol. 56, pp 464-471.

[9] Sozhamannan.G.G et al, (2010) "Failures analysis of particle reinforced metal matrix composites by microstructure based models" Materials and Design vol.3, pp. 3785-3790. 
[10] Hayrettin Ahlatci, et al, (2006) "Wear behaviour of $\mathrm{Al} /\left(\mathrm{Al}_{2} \mathrm{O}_{3 \mathrm{p}}+\mathrm{SiC}_{\mathrm{p}}\right)$ hybrid composites," Tribology International, Vol. 39,.pp. 213-220.

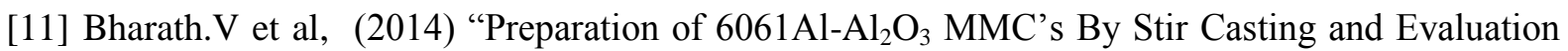
of Mechanical and Wear Properties," Procedia Materials Science 6, pp.1658 - 1667.

[12] Saravanakumar.A .A et al, (2014) "Synthesis and mechanical behaviour of AA 6063-x wt. \% $\mathrm{Al}_{2} \mathrm{O}_{3}-1 \% \mathrm{Gr}(\mathrm{x}=3,6,9$ and 12 wt. \%) hybrid composites" Procedia Engineering, vol. 97, pp. $951-960$.

[13] Md. Habibur Rahman, et al, (2014) "Characterization of silicon carbide reinforced aluminum matrix composites" Procedia Engineering, vol. 90, pp. 103 - 109.

\section{AUTHORS' BIOGRAPHY}

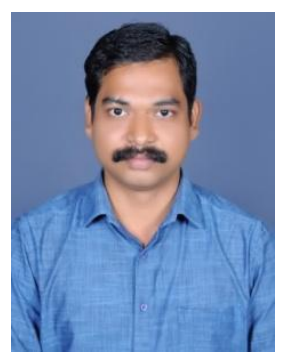

S.Senthil Murugan, is currently working as Assistant Professor in the Department of Mechanical Engineering, Mepco Schlenk Engineering College Sivakasi and doing Ph.D at NIT, Trichy. He has published around 25 research articles in conferences and journals. He guided more than 10 PG degree students. He has undergone summer faculty research fellowship at IIT Delhi. He is involving in two govt. funded (MSME) projects. He is the member of Indian Institute of Metals and Indian Society for Technical Education. Areas of interests are welding, metal matrix composite, environmental safety etc

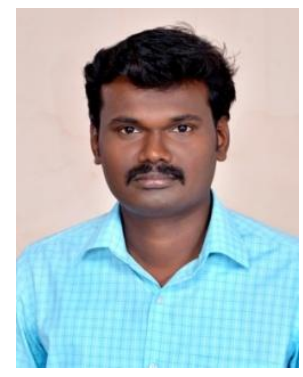

Mr. V. Jegan, completed his M.E. Degree in CAD/CAM from Mepco Schlenk Engineering College, Sivakasi. He is currently working as Assistant Professor in the Department of Mechanical Engineering, S.Veerasamy Chettiar College of Engineering and Technology, Puliyangudi, Tirunelveli District. He has published 5 research articles in conferences and journals. His areas of interests are CAD modelling, Metal Matrix Composite, Tribology etc 